\title{
Entre ideias e interações: a participação dos usuários na politica de assistência social
}

\author{
Between ideas and interactions: user participation in social \\ assistance policy
}

\section{Priscilla Ribeiro dos Santos}

\section{Resumo}

Este artigo examina as relaçôes entre Estado e sociedade na política de assistência social, com foco nos efeitos das interaçóes entre gestores e organizaçóes de usuários no período de 2004 a 2020. Com base em entrevistas e na análise documental, discute-se que, ao assumirem cargos de direção na Secretaria Nacional de Assistência Social, integrantes da comunidade de política passaram a induzir mudanças incrementais no que tange a participação dos usuários não apenas nos conselhos, mas na oferta dos serviços socioassistenciais. Tais mudanças dependeram das potencialidades historicamente criadas dentro e fora da esfera estatal, sendo que o ingresso de novos atores societais no Conselho Nacional de Assistência Social, a partir de 2012, possibilitou experimentaçôes que resultaram na criação do Fórum Nacional de Usuários do Sistema Único de Assistência Social.

\section{Palavras-chave}

Interaçôes Socioestatais; Assistência Social; Usuários; Políticas Públicas.

\section{Abstract}

This article examines the relationship between state and society in the social assistance policy in Brazil, focusing on the effects of interactions between managers and user organizations from 2004 to 2020. Based on interviews and documentary analysis, we argue that, when assuming director positions in the National Secretary of Social Assistance, the members of the policy community began to induce incremental changes regarding the participation of users not only in councils, but in the provision of services. Such changes depended on the potentialities historically created inside and outside the state sphere. Also the entry of new societal actors in the National Council of Social Assistance, since 2012, enabled experimentation that resulted in the creation of the National Users' Forum.

\section{Keywords}

State-society Interaction; Social Assistance; Users; Public Policy. 


\section{Introdução ${ }^{1}$}

No contexto brasileiro pós-transição democrática, uma série de estudos tem analisado as reconfiguraçóes das relaçóes entre Estado e sociedade e seus efeitos em termos da produção de políticas públicas, sobretudo durante o período em que o Partido dos Trabalhadores ocupou o Executivo federal. Diversas pesquisas têm analisado a interpenetração entre política institucional e extrainstitucional e os efeitos do ativismo institucional ${ }^{2}$ nas políticas públicas, sem negligenciar que os resultados alcançados dependem, em certa medida, da forma como grupos da sociedade civil e atores do Estado estabeleceram relaçóes historicamente em cada setor (ABERS, SERAFIM e TATAGIBA, 2014; CAYRES, 2017; ABERS, SILVA e TATAGIBA, 2018). Tendo em vista o estado atual de desenvolvimento da agenda de pesquisas, a interface dos estudos sobre políticas públicas e movimentos sociais tem se mostrado um caminho possível para descrever processos e analisar mudanças de modo a contemplar a complexidade e a fluidez do trânsito de atores na modelagem de políticas públicas nas mais diversas áreas (ROMÃO, MARTELLI e PIRES, 2014; LAVALLE et al., 2018).

A assistência social se destaca entre as áreas de políticas públicas cujos padrôes de interação socioestatal contribuíram decisivamente para moldar a atuação setorial do Estado. Os avanços das três últimas décadas na consolidação da assistência social como direito e política pública mobilizaram diferentes agendas de pesquisas nas Ciências Sociais e, mais especificamente, na Ciência Política. Em que pese a proliferação de estudos sobre a dinâmica de funcionamento e a efetividade dos conselhos municipais de assistência social, ao longo das duas últimas décadas (CUNHA, 2009; ALMEIDA, 2009; ALMEIDA, CARLOS e SILVA, 2016), há uma lacuna na literatura quanto aos efeitos das interações socioestatais na formulação e implementação dessa política pública. Trabalhos recentes como os de Gutierres (2018) e Almeida, Vieira e Kashiwakura (2020) têm buscado explicar as interaçôes socioestatais na assistência social com base na interface com os estudos sobre políticas públicas, movimentos sociais e instituiçôes participativas e na combinação de diferentes estratégias metodológicas.

\footnotetext{
1 A autora agradece as contribuiçōes dos(as) pareceristas para o aprimoramento do texto e o financiamento da Capes de bolsa de estágio de pós-doutoramento, que viabilizou a pesquisa.

${ }^{2} \mathrm{O}$ ativismo institucional é caracterizado por açóes realizadas no interior das instituiçóes, empreendidas por burocratas com vínculos prévios ou não a movimentos sociais, na defesa de causas às quais são simpáticos (ABERS, 2015).
} 
Este artigo dialoga com a referida literatura e examina as relaçóes entre Estado e sociedade na política de assistência social, lançando luz sobre os efeitos das interaçóes entre ativistas que ocuparam cargos de direção na Secretaria Nacional de Assistência Social (SNAS) e as organizaçôes de usuários da assistência social no período de 2004 a 2020. A fim de permitir a triangulaçâo e a validação dos achados empíricos, mobilizamos as técnicas de análise documental e entrevistas. Ao todo, foram selecionados 14 documentos, dentre resoluçóes do Conselho Nacional de Assistência Social (CNAS), cadernos de textos e deliberaçóes das conferências nacionais, atas de reuniôes ordinárias e de processos eleitorais do CNAS, carta de princípios e regimento interno do Fórum Nacional de Usuários do Sistema Único de Assistência Social (FNUSUAS). Em virtude da pandemia da Covid-19 e das medidas de distanciamento social durante o ano de 2020, dois gestores da SNAS foram entrevistados por telefone e um integrante do FNUSUAS optou por responder as questôes por e-mail ${ }^{3}$.

Dentre os resultados, discuto que, ao assumirem cargos de direção na SNAS, os integrantes da comunidade de política passaram a induzir mudanças incrementais na política de assistência social no que tange a participaçáo dos usuários não apenas nos conselhos e conferências, mas no cotidiano da oferta dos serviços socioassistenciais. As mudanças no desenho da política dependeram das potencialidades historicamente criadas dentro e fora da esfera estatal, sendo que os repertórios de participaçáo institucionalizada, como conselho e conferências, foram acionados em diferentes momentos. Ademais, o ingresso de novas organizaçôes e movimentos de usuários no CNAS, a partir de 2012, possibilitou novas experimentaçóes nas interaçóes socioestatais. Tais dinâmicas resultaram na criação do Fórum Nacional de Usuários do SUAS. Nesse sentido, este artigo visa contribuir à agenda de pesquisas sobre as inovaçôes democráticas e sua efetividade ao argumentar que as interações socioestatais podem não só produzir mudanças nas políticas públicas, como também impactar a organização e a atuação dos atores societais que compóem, estruturam e disputam as arenas setoriais.

\footnotetext{
${ }^{3}$ As entrevistas abordaram questôes relativas à participação dos usuários na assistência social e à formação do Fórum Nacional dos Usuários do SUAS. Todo o material foi registrado em arquivos de áudio e texto com o consentimento oral ou por escrito dos participantes. Suas identidades foram preservadas pela referência geral de "entrevistado", mantendo-se apenas o registro da ordem de realização ao longo do texto.
} 


\section{Entre ideias, atores e interações: uma perspectiva relacional para a análise de politicas públicas}

Tendo em vista que as fronteiras entre Estado e sociedade são imprecisas e permeáveis, a agenda de pesquisas sobre as interaçóes socioestatais tem refutado pressupostos dualistas, que caracterizam os movimentos sociais como atores externos ao Estado e que entendem as relaçôes entre ambos desde o prisma da "cooptação" do ativismo político. Ainda, recusam abordagens centradas na agência, concebendo que arranjos institucionais, contextos políticos e coalizóes de governo são variáveis relevantes que afetam escolhas e açôes em virtude da identificação de oportunidades e constrangimentos para a mobilização dos grupos (ABERS, SILVA e TATAGIBA, 2018; LAVALLE et al., 2018). No entanto, as críticas ao conceito de estrutura de oportunidade política alertam que os movimentos não são apenas reativos a oportunidades políticas externas, uma vez que estes criam oportunidades para si e para os demais atores envolvidos (TARROW, 1994).

Parte dessa literatura tem enfatizado uma abordagem relacional na construção de ideias de políticas públicas ${ }^{4}$ ao entender que, nas interaçôes, as ideias são criadas e modificadas (ABERS, SILVA e TATAGIBA, 2018; SZWAKO e PERISSINOTTO, 2018). Essa interpretação é particularmente interessante para a compreensão das mudanças no desenho de políticas públicas, uma vez que enfatiza as dinâmicas de interação e a agência dos atores envolvidos. De acordo com essa perspectiva, os atores políticos têm acesso diferenciado aos recursos materiais e simbólicos em virtude das configuraçôes de poder específicas a cada setor de política pública, mas, ao mesmo tempo, podem usar os recursos de que dispóem para criativamente construir novas interaçôes. A produção das ideias ocorre nas interaçóes com aliados, concorrentes e adversários políticos, sendo que os resultados dependerão da forma como as interaçôes se estruturam e se desenvolvem (TATAGIBA, ABERS e SILVA, 2018).

As mudanças nas políticas públicas são explicadas em termos das interações de diferentes atores em redes e comunidades de políticas ${ }^{5}$, importando para as análises a trajetória institucional de cada política, a conformação da burocracia e a múltipla filiação de ativistas a partidos, movimentos sociais, órgãos de governo e/ou associaçôes

\footnotetext{
${ }^{4}$ Para uma síntese da literatura sobre a "virada ideacional", ver Perissinotto e Stumm (2017).

${ }^{5}$ Por comunidades de políticas entenda-se um grupo relativamente estável de participantes que transita nas fronteiras entre Estado e sociedade e busca afetar os processos decisórios pelo compartilhamento dos “[...] mesmos valores e visão sobre quais devem ser os resultados da política setorial" (CORTES, 2015, p. 132).
} 
profissionais. As comunidades de políticas constituem um importante espaço de compartilhamento, experimentaçáo, debate e difusão de ideias entre seus participantes e têm potencial para inserir temas e questóes na agenda governamental ou mudar os rumos de políticas públicas já existentes (BARCELOS, PEREIRA e SILVA, 2017). Ao gerarem o entendimento sobre ideias, temas e orientaçóes comuns aos membros, as comunidades de políticas acabam por reforçar a integração entre seus participantes. Enquanto algumas ideias são descartadas, outras se mostram viáveis e adequadas aos valores do grupo e passam a disputar a formação da agenda, buscando chamar a atenção dos decisores políticos (SABATIER e WEIBLE, 2007). Tendo em vista que, no processo de produção de política, os problemas não estão necessariamente ligados a soluçóes, os integrantes de comunidades de políticas atuam de modo a criar e a disseminar uma interpretação específica sobre o problema que irá ser objeto da política (KINGDON, 1995), buscando as arenas políticas favoráveis para a apresentação de suas ideias.

\section{Interações socioestatais na politica de assistência social}

Para compreender as mudanças nas rotinas de interação Estado e sociedade na assistência social, é preciso considerar sua conformação histórica, os grupos de interesse e as comunidades de políticas envolvidas na arena política setorial. Em linhas gerais, diversos estudos destacam como especificidades da assistência social a forte atuação das entidades privadas, a baixa capacidade de mobilização por parte de seus usuários e densas redes formadas por uma comunidade de política com atores que mantêm múltiplas filiaçôes (CUNHA, 2009; RAICHELIS, 2011; CORTES, 2015; GUTIERRES, 2018).

Sem o objetivo de resgatar o histórico das açóes públicas de assistência social, interessa aos propósitos deste artigo que a restrita atuação do Estado fortaleceu as entidades privadas e beneficentes na prestação de serviços ao longo das décadas. A intervenção do Estado na assistência social se limitava ao apoio, via subsídios e isençóes, ao setor privado, cuja oferta de serviços era orientada por forte apelo filantrópico, com destaque para as obras sociais vinculadas à Igreja Católica.

A concepção conservadora que, durante décadas, atrelou a assistência social à filantropia trouxe dificuldades para o reconhecimento do usuário como cidadáo e sujeito de direitos, afetando suas formas de organizaçáo política e a construção de identidades coletivas compartilhadas (RAICHELIS, 2011). Ademais, é preciso considerar que não apenas a associação entre assistência social e filantropia impactou a tradição associativa dos usuários, mas a exposiçáo desses grupos a uma série de 
vulnerabilidades e riscos sociais ligados à sobrevivência e à manutenção dos laços comunitários e familiares dificultou sua organizaçáo e mobilização em torno da reivindicação de direitos sociais.

A formação de uma comunidade de política na assistência teve origem na mobilização que antecedeu sua regulamentação. As articulações e alianças construídas após o veto presidencial ao primeiro projeto de lei orgânica, no início da década de 1990, deram origem a uma comunidade formada majoritariamente por atores oriundos dos campos profissional e acadêmico do Serviço Social, que atuavam junto a partidos políticos, centrais sindicais e organizaçóes não-governamentais de assessoramento a movimentos sociais (MARGARITES, 2019; GUTIERRES, 2018). Seus integrantes passaram a atuar de forma organizada a fim de produzir mudanças pelo deslocamento da assistência do campo da filantropia para o da política pública.

Em que pese a forte atuaçáo por parte dos atores oriundos dos campos acadêmico e profissional do Serviço Social, a participação dos grupos sociais historicamente submetidos a processos de vulnerabilização e inserção precária no mercado de trabalho foi reduzida na conformação da assistência social como política pública (RAICHELIS, 2011; YAZBEK, 2015; CUNHA, 2009). Participaram dos trabalhos constituintes e da discussão da Lei Orgânica da Assistência Social (LOAS) um pequeno número de organizaçôes e movimentos sociais, com níveis diversificados de organização, tais como os movimentos pelos direitos dos idosos, das pessoas com deficiência e de meninos e meninas de rua e organizaçóes náo-governamentais de assessoramento a movimentos sociais, como o Instituto Brasileiro de Análises Sociais e Econômicas (IBASE) e a Associação Brasileira de ONGs (ABONG) (RAICHELIS, 2011).

Nesse contexto, os sentidos da participação eram amplos e tinham tanto o apelo de assegurar o cumprimento dos direitos socioassistenciais, recém inscritos constitucionalmente, quanto visavam romper com práticas clientelistas e personalistas de utilização dos recursos públicos pela ampliação da regulação estatal sobre a atuação das entidades privadas e pela promoção da transparência e do controle societal ${ }^{6}$

\footnotetext{
${ }^{6} \mathrm{O}$ conceito de controle societal é mobilizado para compreender a ação de atores coletivos, sejam eles formais e não-formais, que "falam em nome de alguém", na provisão de serviços públicos, viabilizando um controle externo ao Estado (AMÂNCIO, SERAFIM e DOWBOR, 2011). Em linhas gerais, o controle societal nas políticas públicas tem por objetivos encaminhar demandas e preferências ao Estado de modo a influenciar a tomada de decisóes, e fiscalizar as açóes governamentais com base nos princípios da publicidade e da transparência de modo a promover maior responsividade por parte do poder público.
} 
(CUNHA, 2009). Como, até esse momento, era forte a interlocução do Estado com as entidades filantrópicas, os novos atores da assistência social, que se mobilizaram no contexto da LOAS, passaram a reivindicar maior influência na tomada de decisóes e na fiscalização dos recursos públicos pela sua participação em conselhos e conferências ${ }^{7}$.

A defesa de um repertório de interação entre Estado e sociedade via participação institucionalizada em conselhos e conferências remonta ao movimento de renovaçáo do Serviço Social, que se iniciou na década de 1980. Com base nas contribuiçóes da teoria crítica, o Estado passou a ser reconhecido e reivindicado como uma arena legítima para a disputa de projetos políticos, sendo que a participação passou a ser estratégica para pensar a atuação do profissional do Serviço Social na sua relação com os usuários (IAMAMOTO, 1994). Ainda, o trânsito entre gestão, academia e partido contribuiu para o compartilhamento de experiências exitosas de participaçáa em âmbito local nas administraçóes do Partido dos Trabalhadores, de modo a conformar a defesa de um sistema descentralizado e com participação da populaçáo, aos moldes do Sistema Único de Saúde.

Tendo em vista que a criação de instâncias de participação institucionalizada na assistência social antecedeu o adensamento das redes de movimentos sociais e organizaçôes representativas do seu público-alvo, náo raro as entidades privadas e as organizaçóes de trabalhadores tomaram para si a tarefa de representar os usuários. Num contexto de desigualdades de recursos e de frágil ancoragem societária, mesmo o princípio da paridade e o caráter deliberativo dos conselhos de assistência social podem reforçar desequilíbrios nos processos decisórios, favorecendo a atuação dos gestores e das entidades prestadoras de serviços, que dispóem de mais recursos organizacionais (FUKS e PERISSINOTTO, 2006; ALMEIDA, CARLOS e SILVA, 2016). Em virtude disso, a manifestação dos interesses dos usuários esteve dependente da articulação ora com entidades socioassistenciais, ora com entidades de trabalhadores, as quais, via de regra, detinham maiores recursos (financeiros, organizacionais e informacionais) para disputar os espaços institucionais disponíveis.

\footnotetext{
${ }^{7}$ Os conselhos de assistência social são instâncias permanentes, paritárias e deliberativas, que têm por objetivos normatizar, acompanhar, avaliar e fiscalizar programas e serviços. Já as conferências têm o papel de avaliar e definir diretrizes para o setor. Vale lembrar que, com a LOAS, a criação de conselhos com composiçáo paritária entre governo e sociedade civil passou a ser um dos requisitos para o repasse de recursos federais para estados e municípios.
} 


\section{A participação dos usuários no SUAS}

A criação do Ministério de Desenvolvimento Social e Combate à Fome, em 2004, refletiu décadas de luta da comunidade de política da assistência social. Tendo como referência as categorias formuladas por Abers, Serafim e Tatagiba (2014) para analisar as rotinas de interação Estado e sociedade nas políticas de desenvolvimento agrário, política urbana e segurança pública, é possível identificar combinações diversas no caso da assistência social entre rotinas de interação baseadas na participação institucionalizada (conselhos e conferências), na política de proximidade (contatos pessoais e negociaçóes diretas entre atores do Estado e da sociedade civil) e na ocupação de cargos da burocracia. A ocupaçáo de cargos por parte dos integrantes da comunidade de política na recém-criada Secretaria Nacional de Assistência Social permitiu experimentaçôes diversas, ora reforçando rotinas anteriores de interação socioestatal, ora criando novas formas de negociação, colaboração e diálogo, inclusive com o segmento de usuários que, historicamente, teve frágil inserção nas arenas estatais.

Considerando que ideias são um conjunto de crenças que refletem determinada visão de mundo, a produção das políticas engendra menos a utilização de técnicas formais de solução de problemas e mais o processo argumentativo, de disputa sobre critérios de classificação, interpretação e representação simbólica das ideias que guiam as açôes dos indivíduos (STONE, 2002). A disputa sobre as ideias está no centro do processo de produçáo de políticas, uma vez que elas constroem problemas que seráo objeto da ação governamental e incidem sobre a especificação de alternativas. Quando ativistas passaram a atuar como decisores políticos, as ideias defendidas pela comunidade de política ganharam força e buscaram modificar o arcabouço institucional e normativo em uma perspectiva garantidora de direitos, a exemplo da questão do fim da certificação das entidades beneficentes pelo CNAS (CORTES, 2015).

Quanto à questão da participação dos usuários, a circulação de ideias, a busca de apoiadores e a especificação de alternativas ocorreram de forma simultânea em diferentes espaços institucionais, de modo a construir um entendimento comum sobre a necessidade de ruptura com o legado da filantropia que, por décadas, reproduziu práticas conservadoras com base na tutela e no estigma dos usuários. Nesse sentido, a participaçáo passou a ser reivindicada como um direito socioassistencial, que tem o efeito de promover a autonomia e o exercício da cidadania por parte dos usuários. Esse enquadramento está presente no documento Política Nacional de Assistência Social, de 2004, conforme o seguinte trecho: 
A concepção de doação, caridade, favor, bondade e ajuda que, tradicionalmente, caracterizou essa ação [da assistência social], reproduz usuários como pessoas dependentes, frágeis, vitimizadas, tuteladas por entidades e organizaçóes que lhes 'assistiam' e se pronunciavam em seu nome. [...] Assim, há que se produzir uma metodologia que se constitua ao mesmo tempo em resgate de participaçáo de indivíduos dispersos e desorganizados, e habilitação para que a política de assistência social seja assumida na perspectiva de direitos publicizados e controlados pelos seus usuários. Um dos grandes desafios da construção dessa política é a criação de mecanismos que venham garantir a participação dos usuários nos conselhos e fóruns enquanto sujeitos não mais sub-representados. (BRASIL, 2005, p. 52-53).

A comunidade de política passou a buscar apoio à questão de modo a aproveitar a conjuntura favorável às mudanças. Nesse contexto, a disputa em torno de um novo enquadramento sobre a participação dos usuários na assistência social também ocorreu nos ciclos conferenciais. Durante os governos Lula (2003-2010) e Dilma (2011-2016), as conferências cumpriram importante papel na discussão e na seleção de temas que passaram a ser objeto da açáo governamental nas mais diversas áreas de políticas públicas, sendo caracterizadas pela literatura como um sistema integrado de participação e deliberação entre os diferentes níveis de governo (FARIA, SILVA e LINS, 2012). Em virtude de seu caráter inovador, diversos estudos se dedicaram a analisar o sucesso ou o fracasso das experiências em termos da qualidade da deliberaçáo e do impacto das propostas aprovadas na atividade legislativa e na formulação das políticas públicas $^{8}$ (FARIA, SILVA e LINS, 2012; POGREBINSCHI e SANTOS, 2011).

Nesses espaços, que contam com intensa mobilização de atores societais, as ideias circulam em busca de apoiadores, haja vista a centralidade das conferências na definição de diretrizes para as políticas públicas. Quanto à questão da participação dos usuários, já em 2005 é possível identificar a preocupação com a desmobilização do segmento, sendo considerada a possibilidade de "reativaçáo" dos fóruns da assistência social como espaços de articulação de movimentos e organizaçôes da sociedade civil (PEDRINI e PINHEIRO, 2005). Também o caderno de textos da VII Conferência Nacional de Assistência Social, de 2009, identificou um "vazio de representaçáo

\footnotetext{
${ }^{8}$ Para um balanço sobre o debate da efetividade das conferências de políticas públicas, sugiro Petinelli (2017) e a coletânea de artigos organizada por Avritzer e Souza (2013).
} 
própria dos usuários" e sugeriu "repensar suas formas de representação" a fim de garantir sua participação nos conselhos, conforme o seguinte trecho:

\begin{abstract}
Essa questão [a participação dos usuários nos conselhos] permanece como grande desafio, sendo necessário repensar as formas de representação dos usuários, investir nas articulaçóes com os movimentos sociais e associaçóes populares, colaborar para estimular sua auto-organização e autorrepresentação, considerando que os usuários permanecem subrepresentados em grande parte dos conselhos. De fato, há um vazio de representação própria dos usuários, das suas associaçóes e formas autônomas de organização (BRASIL, 2009, p. 18).
\end{abstract}

Se, por um lado, as conferências contribuíram para fomentar o debate e mobilizar o apoio às ideias defendidas pela comunidade de política, por outro, a conquista de espaços institucionais consistia numa das principais estratégias para promover mudanças. A fim de modificar o desenho da política pública e incidir nos processos decisórios, os integrantes da comunidade de política buscaram assegurar mandatos no Conselho Nacional de Assistência Social (CNAS) e estabelecer dinâmicas de cooperação com atores societais sobre determinados temas. Em virtude de sua centralidade como irradiador de normatização, o CNAS foi considerado como o caminho mais curto e rápido para viabilizar mudanças por meio de suas resoluçóes (CORTES, 2015).

Em 2006, foi editada a primeira resoluçáo do CNAS sobre o entendimento acerca dos critérios de habilitação de representantes de usuários e suas organizações aos processos eleitorais dos conselhos de assistência social. Até o momento, o entendimento derivava do artigo 17 da LOAS, que regulamentava a composição do CNAS. No preâmbulo, a Resolução do CNAS no 24/2006 considerou que novos grupos passaram a compor o público-alvo da assistência social e que estes têm iniciado seu processo organizativo, sem necessariamente atender aos critérios de estruturação burocráticoadministrativa das organizaçôes juridicamente constituídas (BRASIL, 2006). Nesse sentido, definiu que os representantes de usuários são pessoas vinculadas aos programas, projetos, serviços e benefícios, organizadas sob diversas formas, em grupos que têm como objetivo a luta por direitos, como associaçóes, movimentos sociais, fóruns, redes ou outras denominaçôes, sob diferentes formas de constituição jurídica, política ou social (BRASIL, 2006). 
Já as organizaçóes de usuários são aquelas juridicamente constituídas que têm entre seus objetivos, estatutariamente, a defesa dos direitos de indivíduos e grupos vinculados à Política Nacional de Assistência Social (PNAS), "[...] sendo caracterizado seu protagonismo na organização mediante participação efetiva nos órgãos diretivos que os representam, por meio da sua própria participação ou de seu representante legal, quando for o caso" (BRASIL, 2006). Nota-se que, para ser reconhecida como uma organização representativa dos usuários, a resolução orienta que é preciso garantir a atuação dos usuários nos órgãos diretivos a fim de evitar que outros atores ocupem os espaços de interlocução para si. Com a obrigatoriedade da comprovação da participação dos usuários nas instâncias diretivas das organizaçóes, havia a expectativa de se minimizar o problema relacionado às entidades que "falavam" em nome dos usuários. No entanto, a questáo era complexa e o cumprimento do normativo náo resolveria o problema histórico da frágil inclusão dos usuários nas instâncias participativas. Cientes disso, outras estratégias foram mobilizadas por parte daqueles que buscavam construir novas formas de interação entre o Estado e os usuários da assistência social.

Para além do reconhecimento de formas variadas de organização de usuários e de comprovação da atuação destes junto aos órgãos diretores dessas organizaçóes, construiu-se a ideia de que era preciso promover sua participaçáo no planejamento e na avaliaçáo dos serviços, de modo a gerar conhecimento sobre os direitos socioassistenciais e estimular a organizaçáo dos usuários no âmbito local - como pode se depreender do seguinte trecho da fala de Raquel Raichelis, pesquisadora e integrante da comunidade de política, durante a X Conferência Nacional:

Quanto maior a mobilização fora dos conselhos mais os conselhos, as representaçôes terão força para exigir que os gestores cumpram aquilo que foi deliberado e aquilo que foi pactuado nos conselhos. Por isso eu diria que é preciso investir na participação, não só nos conselhos, nos fóruns, nas assembleias, mas é preciso investir na participação, na perspectiva que o professor Pedro Pontual colocou, no cotidiano dos serviços, é preciso investir no trabalho de base com os usuários nos territórios onde estáo os CRAS, os CREAS, o Centro POP, porque o protagonismo dos usuários não se faz apenas nas conferências e conselhos, mas se faz no cotidiano do trabalho em que esses serviços são realizados. (CONFERÊNCIA NACIONAL DE ASSISTÊNCIA SOCIAL, 2015, p. 89).

Com a padronização dos serviços e programas, o serviço de proteção e atendimento integral à família (PAIF) incluiu a participação dos usuários nas unidades 
de atendimento como estratégia para garantir seu protagonismo e autonomia, prevenir a ruptura dos vínculos comunitários e fomentar o exercício da cidadania (BRASIL, 2014b). Dentre as aquisições dos usuários que acessam esse serviço, espera-se que estes possam vivenciar experiências de participaçáo cidadã por meio de fóruns, conselhos, movimentos sociais, organizaçóes comunitárias e outros espaços de organização social (idem, p. 14).

A segunda Norma Operacional Básica do SUAS, de 2012, dedicou atenção especial à participação dos usuários nos conselhos e no cotidiano de oferta dos serviços socioassistenciais, sugerindo estratégias aos gestores públicos que contemplam desde a ampla divulgação do cronograma e pautas de reunióes nas unidades prestadoras de serviços e nos meios de comunicação local à constituição de espaços de diálogos entre gestores, trabalhadores e usuários. Ademais, define que coletivos de usuários, comissóes de bairro, fóruns e outras formas de mobilização são espaços dedicados a desencadear o debate, acompanhamento e proposiçáo de estratégias para o aprimoramento dos serviços (BRASIL, 2013b, p. 51).

Em síntese, desde 2004, os integrantes da comunidade de política situados na SNAS buscaram discutir a questão da participação dos usuários pela interpretação de que sua ausência nos conselhos consistia num dos principais problemas para a superação do legado da tutela e da negação de direitos na assistência social. Ao tornarem-se decisores políticos, passaram a agir estrategicamente na formulação do problema e na escolha das alternativas de solução mais adequadas aos seus valores e visão sobre os resultados desejáveis da política (CORTES, 2015). Todavia, a disputa de ideias em torno da participaçáo dos usuários não se limitou ao debate entre burocratas e especialistas no interior das instâncias de gestão da SNAS, tendo alcançado também as instituiçóes participativas, como as conferências de assistência social e o CNAS. Enquanto as conferências contribuíram para fomentar o debate e mobilizar apoiadores (dentro e fora do aparato estatal), o CNAS foi concebido como a principal arena de disputas sobre a normatização do sistema que estava em formação.

Inicialmente, as conquistas da comunidade de política resultaram em mudanças incrementais no que tange a definição dos critérios de habilitação dos usuários nos processos eleitorais dos conselhos e o fomento à sua mobilização, articulada à oferta dos serviços. No entanto, havia a percepçáo de que era preciso construir alianças para fortalecer as redes associativas de usuários. Assim, a oportunidade para construir açóes colaborativas entre Estado e sociedade surgiu quando novas organizaçóes de usuários passaram a compor o CNAS em 2012. 


\section{"Nada para nós sem nós": a criação do Fórum Nacional de Usuários do SUAS}

A partir de 2004, novos grupos foram reconhecidos pelo Estado como usuários da assistência social e puderam reivindicar seus direitos socioassistenciais, dentre eles, a participação nas instâncias de controle da política. Com a nova PNAS, o público-alvo da assistência social passou a ser designado pelo termo usuários. Na defesa do direito à proteçáo social a todos que dela necessitarem, o direito à assistência social passou a se aplicar a indivíduos e famílias em vulnerabilidade ou risco social, decorrente da pobreza ou não. Em tese, permaneceu o caráter focalizado para concessão de benefícios monetários, como o Benefício de Prestação Continuada e o Programa Bolsa Família, mas ampliou-se o escopo de atuaçáo do Estado no que tange ao atendimento de públicos expostos a riscos sociais diversos, desde aqueles advindos de uma inserção precária no mercado de trabalho até situaçóes de ameaça ou destituição de direitos, o que se deu pela oferta de serviços continuados em dois níveis de proteção social, a básica e a especial.

Com os novos critérios de definição do público-alvo, outros atores societais puderam disputar os processos eleitorais de representaçáo de usuários no CNAS para além das organizaçóes e movimentos de idosos e de pessoas com deficiência, os quais tinham forte presença no colegiado desde sua criação (RAICHELIS, 2011). Os mandatos no CNAS têm duração de dois anos, e cada segmento da sociedade civil (trabalhadores, entidades socioassistenciais e usuários) tem direito a três vagas para conselheiros titulares e três para suplentes. Com base na análise da composição do segmento de usuários no CNAS, no período de 2004 a 2020, verificamos um processo de gradual diversificaçáo, a partir de 2012, pela inclusão de novos movimentos e organizaçóes ligados a mulheres, LGBT, negros, minorias étnicas e população em situação de rua, conforme o Gráfico 1. 
Gráfico 1 - Composição do Conselho Nacional de Assistência Social por conselheiros titulares e suplentes de usuários e organizaçóes de usuários (período 2004-2020)

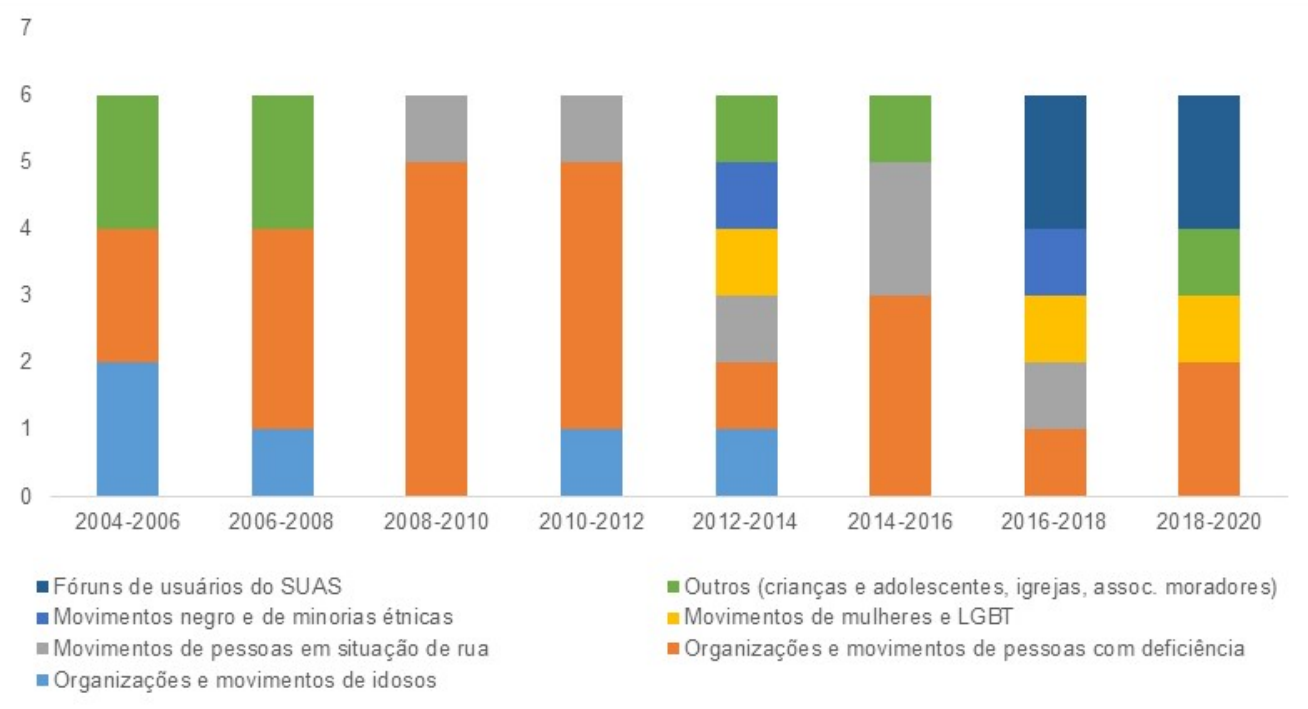

Fonte: Elaboração própria com base em CNAS (BRASIL, c2020).

Até 2008, o segmento de usuários era representado no CNAS apenas por organizaçóes de defesa dos direitos dos idosos, das pessoas com deficiência e de crianças e adolescentes. A presença de organizaçóes ligadas à defesa das pessoas com deficiência foi constante no colegiado de 2004 a 2020, com destaque para sua sobrerrepresentaçáo nos anos de 2008 a 2010. Nos anos mais recentes, as associaçóes e movimentos de idosos têm perdido espaço no CNAS, e, desde 2012, novos coletivos ingressaram, tais como: Fórum e Movimento Nacional da População de Rua ${ }^{9}$, Confederação Nacional de Associaçóes de Moradores, União Brasileira de Mulheres, União de Negros pela Igualdade, Rede Nacional de Pessoas Trans no Brasil, Associação Mayle Sara Kali e Instituto Ecovida.

A equipe ministerial percebeu como uma oportunidade a inclusão de novos atores societais no CNAS e, com eles, buscou desenvolver açóes cooperativas sobre a

\footnotetext{
${ }^{9}$ Em 2008, pela primeira vez, a população adulta em situação de rua conquistou uma vaga no colegiado pelo recém-criado Movimento Nacional da População de Rua (MNPR). Até o momento, o Movimento Nacional de Meninos e Meninas de Rua participava ativamente no CNAS, tendo atuado na discussão da LOAS. As interaçóes entre a equipe ministerial e os coletivos de pessoas em situação de rua se tornaram mais frequentes com a organização do I Encontro Nacional sobre População em Situação de Rua, em 2005, e a realização do primeiro censo e da primeira pesquisa nacional sobre o tema, em 2008.
} 
questão da participação dos usuários, que resultaram na criação do Fórum Nacional de Usuários do SUAS. Vale lembrar que, durante o governo Dilma, ainda era forte a presença de integrantes da comunidade de política na SNAS e na Secretaria de Avaliação e Gestão da Informação (SAGI), a exemplo das secretárias nacionais, Denise Colin e Ieda Castro, de diretores e assessores do Departamento de Gestáo do SUAS da SNAS e da secretária da SAGI e presidente do CNAS (gestão 2012-2014), Luziele Tapajós - apontados nas entrevistas como apoiadores da criação do FNUSUAS.

A opção pela adesão ao formato de fórum se deu em funçáo de experiências anteriores na assistência social de interlocução entre o Estado e as organizaçóes da sociedade civil. A criação do FNUSUAS remonta à ideia de "reativação" de fóruns de assistência social que foram constituídos ao longo dos anos 1990 e tiveram importante papel no momento de implantaçáo dos dispositivos da LOAS. Entretanto, a novidade do FNUSUAS reside na criação de um fórum exclusivo de usuários, que visa agregar os diversos grupos que compóem os públicos da assistência social.

O FNUSUAS foi gestado na IX Conferência Nacional da Assistência Social, em 2013, em plenária com representantes do segmento. De 2013 a 2014, a negociação para a criação do FNUSUAS foi se delineando e ganhando espaço no CNAS e na SNAS. Atuaram ativamente na criaçáo do FNUSUAS conselheiros do CNAS ligados à Organização Nacional de Cegos do Brasil, ao Movimento Nacional de Populaçáo de Rua e ao Instituto Ecovida. A criação formal do fórum ocorreu durante a reunião ampliada e descentralizada do CNAS em novembro de 2014 (Entrevistado 3). O apoio da gestáo e a posição ocupada pelas organizaçóes de usuários no CNAS contribuíram para a negociação da pauta da reuniáo com os demais segmentos da sociedade civil e para a realização de uma oficina com o tema "Mecanismos e modelos de mobilização para a participação de usuários", com a participação de especialistas ${ }^{10}$ (BRASIL, 2014a; Entrevistados 2 e 3). A partir de então, a SNAS passou a disponibilizar recursos técnicos e financeiros para a estruturação do fórum (Entrevistado 3).

A negociação e a combinação criativa de práticas ampliaram as chances de influência entre Estado e coletivos da sociedade civil, conforme discutido por Abers, Serafim e Tatagiba (2014). Na assistência social, as interaçóes entre as ativistas da

\footnotetext{
${ }^{10}$ Edval Bernardino e Joaquina Barata foram citados nas entrevistas como apoiadores da criação do FNUSUAS. Vale destacar que Edval Bernardino tinha atuado como conselheiro do CNAS, na gestão 2008-2010, representando o Conselho Federal do Serviço Social. Na oportunidade, a participação dos usuários nos conselhos já era uma questão pautada por ele e mobilizou parte das discussōes da reunião ampliada do CNAS em abril de 2009. O evento foi considerado uma reunião preparatória para a VII Conferência Nacional de Assistência Social, cujo tema foi "Participação e controle social no SUAS".
} 
SNAS e as organizaçóes de usuários ocorreram por dentro da institucionalidade, sendo que as estruturas da SNAS e do CNAS foram mobilizadas por meio do acesso a recursos materiais e simbólicos. Enquanto os gestores da SNAS disponibilizavam os recursos institucionais de que dispunham, os conselheiros representantes de usuários no CNAS aproveitavam a legitimidade perante os demais segmentos da sociedade civil no conselho e a rede articulada de organizaçóes atuantes no setor para fomentar o debate sobre a organização dos usuários nos estados e municípios. Mesmo num contexto político-institucional de instabilidade, devido à abertura do processo de impeachment da Presidenta Dilma Rousseff, a SNAS garantiu apoio político e financeiro para a participação dos representantes do fórum nas conferências estaduais e apoio técnico para a elaboração da carta de princípios e do regimento interno (Entrevistado 3).

Segundo a carta de princípios, o fórum tem por finalidade "[...] fomentar a articulação política, a mobilização, a formação, o empoderamento, monitoramento, o controle social e representar o coletivo dos/as usuários/as nas instâncias de discussão, deliberação, pactuação, controle e gestão nacional do SUAS” (FNUSUAS, 2015, p. 2). Seu regimento foi aprovado em 2017, estando organizado, além do âmbito nacional, nos níveis municipal, estadual, distrital e regional. Em termos de estrutura, o FNUSUAS conta com uma Coordenação Nacional, composta por representantes indicados pelas cinco regióes para mandatos de três anos, Secretaria Executiva e Plenária Nacional (FNUSUAS, 2017). O FNUSUAS é composto por organizaçôes de usuários existentes e por usuários sem vinculação a coletivos, que acessam serviços e benefícios no âmbito do SUAS.

Em 2015, as mesmas organizaçôes e movimentos que participaram da criação do FNUSUAS também buscaram incidir na redação de uma nova resolução, que caracteriza os usuários e os critérios de habilitação nos processos eleitorais dos conselhos em substituição à resolução anterior, de 2006. A nova resolução não apenas reconheceu diversas formas de organização de usuários, menos institucionalizadas e menos burocratizadas, como reforçou o entendimento de que a participação dos usuários nos conselhos deve estar atrelada à sua atuação junto a coletivos, fóruns, associaçôes, conselhos locais, redes, comissões e associações comunitárias e de moradores (BRASIL, 2015, p. 4).

Garantida a habilitação dos integrantes do FNUSUAS nos processos eleitorais dos conselhos, este passou a disputar mandatos no CNAS. Em virtude de sua forma de organização menos burocratizada e na ausência de inscriçáo no Cadastro Nacional de Pessoas Jurídicas (CNPJ), o FNUSUAS tem reivindicado participação nos processos 
eleitorais de representação da sociedade civil nos conselhos estaduais e municipais a partir desses critérios. Ainda que as resoluçóes do CNAS tenham abrangência nacional, é necessário que as legislaçóes estaduais e municipais da assistência social sofram atualização para que as mudanças sejam implementadas. Para isso, assegurar um mandato no CNAS garantiria recursos institucionais ao fórum para induzir mudanças nos entes subnacionais. Foi então que, nas eleições da gestão 2016-2018, o fórum apresentou duas candidaturas, uma com indicação de filiação ao Fórum Estadual de Usuários do SUAS de Sergipe, e uma pelo Fórum Nacional de Usuários do SUAS. Ambas conquistaram votos suficientes para a conquista de assentos no colegiado.

Desde então, a presença de integrantes do FNUSUAS no CNAS se manteve constante, sendo que seus representantes, ora direta, ora indiretamente, ocuparam a presidência e a vice-presidência do conselho. Diretamente, quando o representante eleito pelo fórum ocupou a presidência ou a vice-presidência, e indiretamente quando integrantes da coordenação executiva do fórum ocuparam o cargo por suas organizaçôes de origem. Atualmente, o FNUSUAS é composto pelas seguintes organizaçóes: Instituto Ecovida (Amapá), Organização dos Cegos do Brasil, Associação Cedro Centro de Estudos e Discussóes Romani-Cigano, Movimento Nacional da População em Situação de Rua, União de Negros Pela Igualdade, Instituto Nacional Afro Origem, Associação de Mulheres Ribeirinhas Vítimas de Escalpelamento da Amazônia e Rede Latino-Americana de Pessoas Trans (Entrevistado 3).

O FNUSUAS expandiu sua capilaridade nos estados e municípios, e seus integrantes passaram a pressionar os órgáos gestores da assistência social para a atualização da legislaçáo de acordo com as novas regulamentaçóes do SUAS. Não raro, seus integrantes, com o apoio do CNAS, têm acionado o Ministério Público nos casos de descumprimento da habilitação dos fóruns nos processos eleitorais dos conselhos. Segundo dados do Censo SUAS de 2018, 37\% dos conselhos municipais afirmaram que sua lei original nunca sofreu alteração, e 15,7\% afirmaram não possuir regimento interno (BRASIL, 2019). Quanto à presença de usuários nos conselhos municipais, houve um discreto aumento que, em parte, pode ser explicado pelo processo de indução gerado pelo pacto de aprimoramento da gestáo municipal ${ }^{11}$. Em 2012, 16,8\% dos conselhos municipais declararam não ter representantes de usuários ou de organizaçóes

\footnotetext{
${ }^{11} \mathrm{O}$ pacto estabeleceu metas e prioridades para a gestão municipal no quadriênio 2014-2017. A seção dedicada ao controle social decidiu "[...] ampliar a participação dos usuários e dos trabalhadores nos conselhos municipais de assistência social com meta de atingir 100\% dos conselhos com representantes de usuários e trabalhadores na representação da sociedade civil” (BRASIL, 2013a, p. 4).
} 
de usuários entre os conselheiros da sociedade civil. Já em 2018, esse número caiu para 11,3\% (BRASIL, 2019).

A questão da participação dos usuários permanece em disputa, e a relação entre os gestores e as organizaçóes da sociedade civil sofreu mudanças a partir da deposição da Presidenta Dilma Rousseff em 2016. A partir desse momento, evidenciou-se o recuo de interaçôes socioestatais orientadas pelo diálogo, cooperação e proximidade, e o avanço de açóes políticas extrainstitucionais de confronto, denúncia e explicitação do conflito por parte dos integrantes da comunidade de política, conforme discutido por Almeida, Vieira e Kashiwakura (2020). A articulação que o fórum vinha construindo com a equipe ministerial foi impactada pela conjuntura pós-impeachment, tendo em vista a troca de alguns quadros da SNAS e o esgotamento de recursos oriundos de organismos internacionais, os quais viabilizavam, por exemplo, a contrataçáo de consultorias e a realização de eventos com a participação dos usuários (Entrevistados 1 e 2). $\mathrm{Na}$ avaliação de uma das integrantes do fórum,

Quando o FNUSUAS nasceu recebemos o apoio total do MDS e SNAS para dar visibilidade as nossas pautas e mobilizaçóes. De 2016 para cá a relaçáo mudou totalmente, não existe apoio para nenhuma açáo e percebemos uma estratégia de desarticulação. Nâo existe qualquer tipo de diálogo, mais (sic) nós continuamos resistindo (Entrevistado 3).

Tendo em vista seu caráter plural e multifacetado, as interaçóes socioestatais podem combinar elementos aparentemente contraditórios, que envolvem a cooperaçáo, a contestação e a busca por autonomia (CARLOS, 2014). As interaçóes entre Estado e sociedade em instituiçóes participativas, como conselhos, podem tanto representar oportunidades políticas aos grupos societais tradicionalmente excluídos das esferas estatais, estimulando o crescimento do associativismo civil e a partilha do poder decisório, como podem produzir restriçóes e constrangimentos de modo a influir no comportamento, nas alianças e nas formas de sua organização (CARLOS, 2014). Dito isso, a atual conjuntura de instabilidade política e de reorientação da relação do Estado com os movimentos sociais tem trazido alguns desafios ao FNUSUAS, que tem buscado combinar a permanência no CNAS com o engajamento em ações de protesto e contestação fora da institucionalidade.

Ainda em 2017, durante a gestão de Michel Temer, destacamos duas açóes coordenadas pela SNAS: a realização do $1^{\circ}$ Encontro Nacional de Usuários, em parceria com o CNAS, e a cooperaçáo entre o Departamento de Gestáo do SUAS 
(DGSUAS/SNAS) com o departamento de Sociologia da Universidade Federal de Minas Gerais para a elaboração de uma pesquisa nacional sobre satisfação dos usuários dos Centros de Referência da Assistência Social (Entrevistado 1).

A adesão a rotinas de protestos e de contestação se fortaleceu já na primeira conferência nacional pós-deposição de Dilma Rousseff em 2017. Entoando versos como "nada para nós sem nós", o fórum demarcou seu distanciamento da equipe governamental e se somou aos protestos contra à redução do orçamento federal na assistência social e contra o programa Criança Feliz. A fim de manter sua autonomia, o fórum tem buscado garantir açóes fora da institucionalidade, articulando-se junto à Frente Nacional em Defesa do SUAS e da Seguridade Social ${ }^{12}$ e a entidades de trabalhadores da assistência social, a exemplo do Conselho Federal de Psicologia. A percepção de que o governo não era um aliado do fórum foi reforçada e outras açóes de protestos foram mobilizadas. Em 2019, diante da recusa do Ministério da Cidadania, sob Governo de Jair Bolsonaro, em manter o calendário conferencial, foi convocada a Conferência Nacional Democrática da Assistência Social. Embora o CNAS não tenha apoiado oficialmente o evento, a presidenta do colegiado, que também era integrante do FNUSUAS, participou ativamente de sua organização.

\section{Considerações finais}

Este artigo analisou as relaçôes entre Estado e sociedade na política de assistência social, dando ênfase aos efeitos das interaçóes entre gestores da SNAS e as organizaçóes de usuários no período de 2004 a 2020. Os integrantes da comunidade de política assumiram protagonismo na condução do debate sobre a participação na assistência social desde o final da década de 1980. Ao assumirem cargos de direção na SNAS, passaram a induzir mudanças incrementais no que tange a participação dos usuários nos conselhos e na oferta dos serviços socioassistenciais. As mudanças no desenho da política dependeram das potencialidades historicamente criadas dentro e fora da esfera estatal, sendo que os repertórios de participação institucionalizada, como conselho e conferências, foram acionados em diferentes momentos. Inicialmente, os ativistas buscaram disseminar nas conferências um enquadramento sobre a questão de forma a garantir maior legitimidade às decisôes pela mobilização de apoiadores. Em

\footnotetext{
${ }^{12}$ A Frente Nacional em Defesa do SUAS e da Seguridade Social se constituiu no contexto de aprovação da Emenda Constitucional 95/2016, que congela os gastos públicos para o período de duas décadas. A Frente reúne parte dos integrantes da comunidade de política que estiveram no comando da SNAS no período de 2004 a 2015, integrantes do FNUSUAS, entidades, fóruns de trabalhadores, instituições não-governamentais, gestores e pesquisadores.
} 
paralelo, atuavam no CNAS a fim de promover mudanças no arcabouço normativo. Quando o conteúdo das resoluçôes aprovadas se mostrou insuficiente para a soluçáo do problema e quando novos atores societais ingressaram no CNAS, a partir de 2012, novas experimentaçóes nas interações socioestatais foram mobilizadas, dando origem ao FNUSUAS. Dito isso, o reconhecimento por parte da comunidade de política das instituiçóes participativas como arenas de disputas legítimas para a formataçáo do sistema em uma perspectiva garantidora de direitos, possibilitou dinâmicas de cooperação entre ativistas e usuários no período analisado. Este estudo de caso sobre a assistência social buscou contribuir à agenda de pesquisas sobre as inovaçôes democráticas e sua efetividade ao conceber que as interaçóes entre Estado e sociedade podem não só produzir mudanças nas políticas públicas, como podem impactar a organização e a atuaçáo dos atores societais que compóem, estruturam e disputam as arenas setoriais, sendo que a conformação histórica da política pública apresenta possibilidades de ação que são criativamente (re)criadas pelos atores em suas interaçôes.

Frente a um ambiente politicamente instável, no qual o governo deixa de ser percebido como aliado, o FNUSUAS tem demonstrado habilidade para combinar diferentes formas de ação e negociação política com base em interaçóes híbridas, que conjugam cooperação, autonomia e conflito para manter relaçôes e garantir espaços e recursos institucionais. Embora recente, o FNUSUAS tem feito uso diversificado e, às vezes, simultâneo de formas de açáo mais ou menos institucionalizadas, tendo em vista as oportunidades, os ganhos e ameaças políticas em um contexto não mais favorável à aberta cooperação entre seus integrantes e a equipe de governo. Por fim, não foi possível explorar neste artigo os efeitos das interaçôes entre Estado e sociedade sobre o funcionamento das instituiçôes participativas em uma conjuntura política desfavorável à inclusão de atores societais nos processos decisórios, sendo a pesquisa comparada uma estratégia analítica bastante promissora para compreender as especificidades de cada área de política pública.

Priscilla Ribeiro dos Santos é Mestra e Doutora em Ciência Politica (UFRGS). Atualmente, realiza estágio de pós-doutorado no Programa de Pós-Graduação em Sociologia (UFRGS). E-mail: priscilla.santos@ufrgs.br. 


\section{Referências}

ABERS, Rebecca. Ativismo na burocracia? $O$ médio escaláo do Programa Bolsa Verde. In: CAVALCANTE, Pedro; LOTTA, Gabriela (Org.). Burocracia de médio escaláo: perfil, trajetória e atuação. Brasília: Enap, 2015. p. 143-175.

ABERS, Rebecca; SERAFIM, Lizandra; TATAGIBA, Luciana. Repertórios de interação Estadosociedade em um Estado heterogêneo: A Experiência na Era Lula. Dados, v. 57, n. 2, p. 325-357, 2014.

ABERS, Rebecca; SILVA, Marcelo K.; TATAGIBA, Luciana. Movimentos sociais e políticas públicas: repensando atores e oportunidades políticas. Lua Nova, n. 105, p. 15-46, 2018.

ALMEIDA, Carla. Conselhos gestores e regulação: a assistência social em tempos de transição. Política \& Sociedade, v. 8, n. 15, p. 251-269, 2009.

ALMEIDA, Carla; CARLOS, Euzeneia; SILVA, Rafael. Efetividade da participação nos conselhos municipais de assistência social do Brasil. Opinião Pública, v. 22, n. 2, p. 250-285, 2016.

ALMEIDA, Débora R.; VIEIRA, Anne K.; KASHIWAKURA, Gabriella. Instituiçôes participativas e repertórios de interação: os Conselhos Nacionais de Saúde e Assistência Social no contexto do impeachment. Revista do Serviço Público, v. 71, n. 1, p. 140-170, 2020.

AMANCIO, Júlia M.; SERAFIM, Lizandra; DOWBOR, Mônica. Microterritorialidade e controle societal. Lua Nova, n. 84, p. 287-314, 2011.

AVRITZER, Leonardo; SOUZA, Clóvis H. L. (Orgs.). Conferências nacionais: atores, dinâmicas e efetividade. Brasília: Ipea, 2013.

BARCELOS, Márcio; PEREIRA, Matheus M.; SILVA, Marcelo K. Redes, campos, coalizóes e comunidades: conectando movimentos sociais e políticas públicas. BIB, n. 82, p. 13-40, 2017.

BRASIL. Conselho Nacional de Assistência Social. Gestóes anteriores. Brasília, c2020. Disponível em: <https://www.blogcnas.com/>. Acesso em: 30 nov. 2020. Blog CNAS.

BRASIL. Ministério da Cidadania. Censo SUAS 2018: Resultados Nacionais, Conselho Municipal de Assistência Social. Brasília: Coordenação-Geral de Planejamento e Vigilância Socioassistencial; Secretaria Nacional de Assistência Social, 2019.

BRASIL. Emenda Constitucional no 95, de 15 de dezembro de 2016. Altera o Ato das Disposiçóes Constitucionais Transitórias, para instituir o Novo Regime Fiscal, e dá outras providências. Diário Oficial da União, 15 dez. 2016.

BRASIL. Conselho Nacional de Assistência Social. Resolução no 11, de 23 de setembro de 2015. Diário Oficial da União, n. 183, Seção 1, p. 75, 24 set. 2015.

BRASIL. Conselho Nacional de Assistência Social. Ata da ordem dos dias 17 a 19 de novembro de 2014. Brasília, 2014a.

BRASIL. Ministério de Desenvolvimento Social. Tipificaçâo Nacional de Serviços Socioassistenciais. reimp. Brasília, 2014b.

BRASIL. Ministério de Desenvolvimento Social. Resolução no 18 , de 15 de julho de 2013. Diário Oficial da União, n. 136, Seção 1, 17 jul. 2013 a.

BRASIL. Ministério do Desenvolvimento Social. Resolução CNAS no 33, de 12 de dezembro de 2012. Diário Oficial da União, Seção 1, p. 155, 03 jan. 2013 b.

BRASIL. Conselho Nacional de Assistência Social. Caderno de Textos: Participação e Controle Social no SUAS. Brasília: CNAS/MDS, 2009. 
BRASIL. Conselho Nacional de Assistência Social. Resolução no 24, de 16 de fevereiro de 2006. Diário Oficial da União, n. 43, Seção 1, p. 67, 03 mar. 2006.

BRASIL. Ministério de Desenvolvimento Social e Combate à Fome. Política Nacional de Assistência Social (PNAS/2004) e Norma Operacional Básica 2005. Brasília, 2005.

CONFERÊNCIA NACIONAL DA ASSISTÊNCIA SOCIAL, 10., 2015. Anais da X Conferência Nacional da Assistência Social. Brasília, 2015.

CARLOS, Euzeneia. Interaçóes socioestatais e efeitos institucionais na ação coletiva: contribuiçóes da análise relacional. In: ROMÃO, Wagner M.; MARTELLI, Carla G.; PIRES, Valdemir (Orgs.). Participação política no Brasil: ação coletiva e interfaces socioestatais. São Paulo: Cultura Acadêmica, 2014. p. 65-98.

CAYRES, Domitila C. Ativismo institucional e interaçóes estado-movimentos sociais. $B I B$, n. 82, p. 81$104,2017$.

CORTES, Soraya V. Policy community defensora de direitos e a transformação do Conselho Nacional de Assistência Social. Sociologias, v. 17, n. 38, p. 122-154, 2015.

CUNHA, Eleonora Schettini. Efetividade deliberativa: estudo comparado de Conselhos Municipais de Assistência Social (1997/2006). 2009. 372 f. Tese (Doutorado em Ciência Política) - Programa de Pós-Graduação em Ciência Política, Universidade Federal de Minas Gerais, Belo Horizonte, 2009.

FARIA, Claudia F.; SILVA, Viviane P.; LINS, Isabella L. Conferências de políticas públicas: um sistema integrado de participação e deliberação? Revista Brasileira de Ciência Política, n. 7, p. 249-284, 2012.

FÓRUM NACIONAL DOS USUÁRIOS DO SUAS (FNUSUAS). Regimento interno. 2017. Disponível em: <https://forumusuariosuas.files.wordpress.com/2017/04/regimento-interno-fnusuas18-04-2017.pdf>. Acesso em: 14 ago. 2020.

FÓRUM NACIONAL DOS USUÁRIOS DO SUAS (FNUSUAS). Carta de princípios. 2015. Disponível em: <https://forumusuariosuas.files.wordpress.com/2016/04/carta-deprincicc81pios_fnusuas.pdf>. Acesso em: 14 ago. 2020.

FUKS, Mario; PERISSINOTTO, Renato. Recursos, decisão e poder: conselhos gestores de políticas públicas de Curitiba. Revista Brasileira de Ciências Sociais, v. 21, n. 60, p. 67-81, 2006.

GUTIERRES, Kellen A. Estudo de trajetórias e interaçóes socioestatais: mútua constituição entre movimento social e a política pública de assistência social. Lua Nova, n. 105, p. 81-114, 2018.

IAMAMOTO, Marilda. Renovação e conservadorismo no serviço social: ensaios críticos. São Paulo: Cortez, 1994.

KINGDON, John. Agendas, alternatives and public policies. New York: Addison Wesley Longman, 1995.

LAVALLE, Adrian G. et al. Movimentos sociais, institucionalização e domínios de agência. In: SZWAKO, José et al. Movimentos sociais e institucionalização: políticas sociais, raça e gênero no Brasil pós-transição [online]. Rio de Janeiro: EDUERJ, 2018. p. 20-86.

MARGARITES, Gustavo C. A constituição da assistência social como um campo de açáo estratégica no Estado brasileiro. 2019. 280 f. Tese (Doutorado em Sociologia) - Programa de Pós-Graduação em Sociologia, Universidade Federal do Rio Grande do Sul, Porto Alegre, 2019.

PEDRINI, Dalila M.; PINHEIRO, Márcia M. Biondi. O controle social na Assistência Social. In: MINISTÉRIO DO DESENVOLVIMENTO SOCIAL E COMBATE À FOME. Cadernos de Estudos Desenvolvimento Social em Debate, Supl., p. 34-43, 2005. 
PERISSINOTTO, Renato; STUMM, Michelli G. A virada ideacional: quando e como ideias importam. Rev. Sociol. Polit., v. 25, n. 64, p. 121-148, 2017.

PETINELLI, Viviane. A quem servem as conferências de políticas públicas? Desenho institucional e atores beneficiados. Opinião Pública, v. 23, n. 3, p. 612-646, 2017.

POGREBINSCHI, Thamy; SANTOS, Fabiano. Participação como representação: o impacto das conferências nacionais de políticas públicas no Congresso Nacional. Dados, v. 54, n. 3, p.259-305, 2011.

RAICHELIS, Raquel. Esfera pública e conselhos de assistência social: Caminhos da construção democrática. São Paulo: Cortez, 2011.

ROMÃO, Wagner M.; MARTELLI, Carla G.; PIRES, Valdemir (Orgs.). Participaçáo política no Brasil: ação coletiva e interfaces socioestatais. São Paulo: Cultura Acadêmica, 2014.

SABATIER, Paul; WEIBLE, Christopher M. The advocacy coalition framework: innovation and clarifications. In: SABATIER, Paul (Ed.). Theories of the policy process. Cambridge: Westview Press, 2007. p. 189-220.

STONE, Deborah. Policy paradox: the art of political decision making. Nova York: Norton \& Company, 2002.

SZWAKO, José; PERISSINOTTO, Renato. Ideias e interaçôes: a generificação de duas políticas públicas no Paraguai. In: SZWAKO, José et al. Movimentos sociais e institucionalização: políticas sociais, raça e gênero no Brasil pós-transição [online]. Rio de Janeiro: EDUERJ, 2018. p. 375-406.

TARROW, Sidney. Power in movement: social movements, collective action and politics. Cambridge: Cambridge University Press, 1994.

TATAGIBA, Luciana; ABERS, Rebecca; SILVA, Marcelo K. Movimentos sociais e políticas públicas: ideias e experiências na construção de modelos alternativos. In: PIRES, Roberto; LOTTA, Gabriela.; OLIVEIRA, Vanessa E. (Orgs.). Burocracia e políticas públicas no Brasil: interseçóes analíticas. Brasília: Ipea/Enap, 2018. p. 106-138.

YAZBEK, Maria C. Classes subalternas e assistência social. São Paulo: Cortez, 2015.

Texto recebido em 16 de dezembro de 2020. Aprovado em 02 de fevereiro de 2021. 